\title{
A Description of a Recording Porometer and a Note on Stomatal Behaviour during Wilting.
}

\author{
BY \\ C. G. P. LAIDLAW, M.A., \\ AND \\ R. C, KNIGHT, B.Sc. ${ }^{1}$ \\ With three Figures in the Text.
}

$\mathrm{T}$ experiments involving the estimation of stomatal aperture it is often necessary to obtain a continuous record of stomatal behaviour over a considerable period. The necessity for making continuous observations by any of the usual methods is inconvenient, especially when observations of other phenomena have to be made. Balls (1) has used with success an automatic recording porometer, the Stomatograph, the chief objection to which is its high cost. More recently, Neilson Jones (2) has devised a recording porometer which can be constructed in the laboratory from inexpensive material. The apparatus here described is also of simple construction, and it has been found very satisfactory for stomatal investigations.

The apparatus is essentially a self-recording modification of the aspirator porometer which has been described by one of us in a previous paper (3). In that paper it should have been stated that Balls (1, p. 34) has experimented with a recording aspirator, which, however, was subsequently abandoned for the type of apparatus of his Stomatograph.

In the present apparatus a head of water in a constant-pressure aspirator is employed to draw air through the leaf, and the speed of the air-stream (and therefore the relative size of the stomatal apertures) is measured by the rate at which water flows from the aspirator.

The apparatus is shown diagrammatically in Fig. I. A is a widemouthed bottle fitted with a rubber stopper pierced by three holes, through

1 This work was undertaken by both authors jointly, but owing to the death of Mr. Laidlaw, who fell at Richebourg l'Avouée in April, I9I5, the second anthor is alone responsible for the statements in the paper.

[Annals of Botany, Vol. XXX. No. CXVII. January, I9ı6.] 
which pass three glass tubes. Tube B is connected with the leaf-chamber attached to the plant, and passes almost to the bottom of the bottle. The air drawn from the leaf enters the bottle through B. C is the water-exit tube through which water is siphoned from the bottle through tube $\mathrm{E}$, whence it flows drop by drop on to the recorder. The siphon tube $\mathrm{C}$ is provided with a three-way stopcock, $\mathrm{F}$, by means of which the aspirator bottle can be refilled from the funnel when necessary, air escaping through the tube and stopcock D during the operation. The head of water used to draw air through the leaf is regulated by the difference in level between the lower

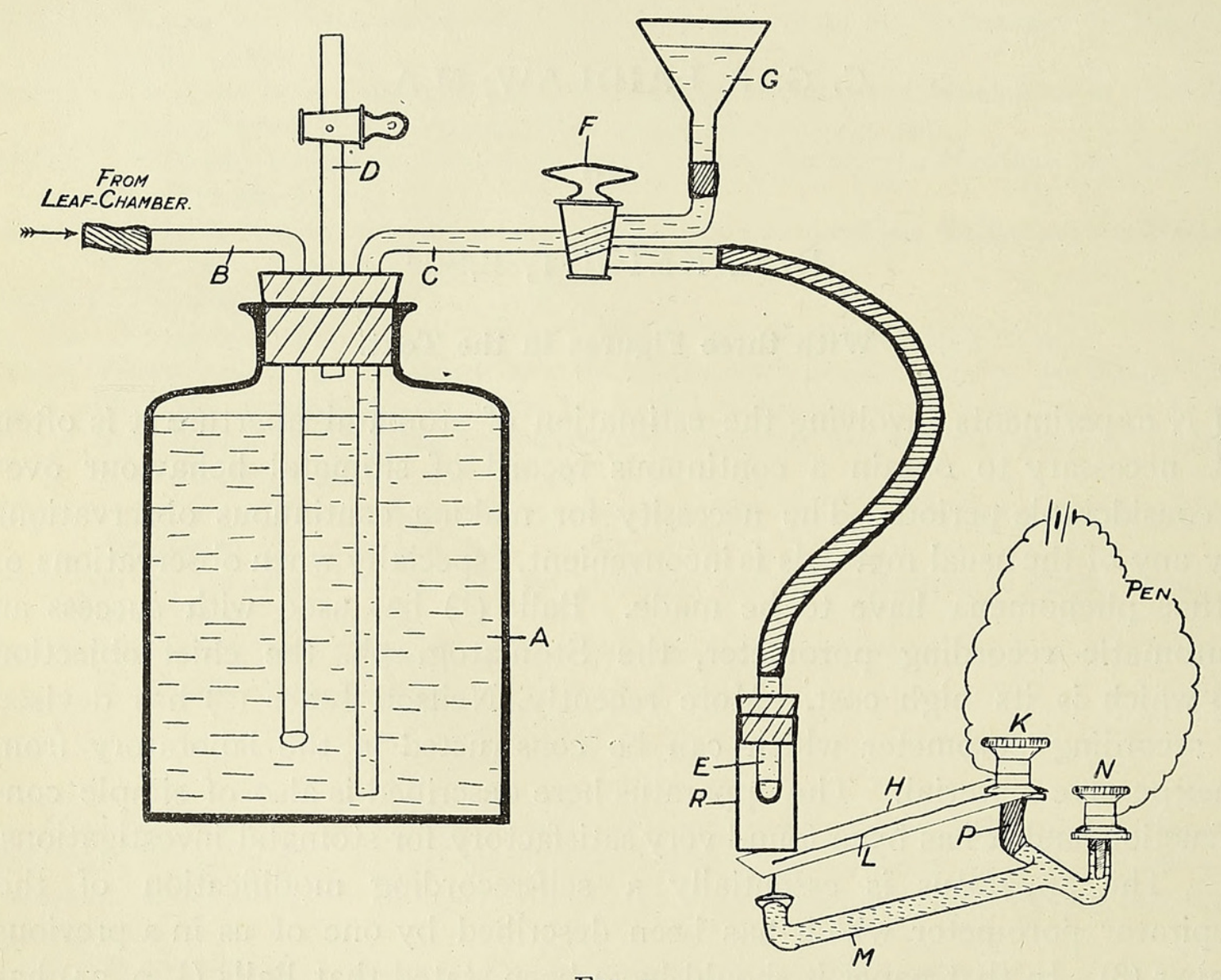

FIG. I.

ends of tubes B and E. E is connected to the siphon tube, C, by a piece of thick-walled rubber tubing, so that any required pressure difference may easily be obtained by raising or lowering $\mathrm{E}$.

When the rate of dropping is slow, each drop remains at the end. of tube $\mathrm{E}$ for some time before falling, and there is a danger of its being prematurely removed by air currents. To prevent this, $\mathrm{E}$ is surrounded by a wide tube, $R$, secured by a rubber stopper. The inside of $R$ is kept damp by lining it with wet blotting-paper, in order to reduce evaporation from the drop, which might conceivably be considerable under some conditions.

The speed at which the water flows from $\mathrm{E}$ is measured by the frequency of the drops as determined by the recorder. This consists 
of a strip of mica, $\mathrm{H}$, secured by a binding-screw, $\mathrm{K}$, at one end, carrying a thin platinum wire, $\mathrm{L}$, which is bent downwards at the free end and poised over mercury in a glass tube, $\mathrm{M}$, which connects with the binding-screw $\mathrm{N}$. The binding-screws are secured in their respective tubes by means of sealingwax, and $\mathrm{K}$ is separated from the mercury by a sealing-wax plug, $\mathrm{P}$. Leads from $\mathrm{K}$ and $\mathrm{N}$ are carried to a battery and the terminals of a magnetic pen, writing on an ordinary clockwork recording drum. We have used and found satisfactory a drum supplied by the Cambridge Scientific Instrument Company. It is about $\mathrm{I} 3 \mathrm{~cm}$. in diameter and revolves once in about twenty-seven minutes, being long enough to record continuously for forty hours.

The mica strip is placed so that the drops from $\mathrm{E}$ impinge upon its free end. Thus, when a drop falls, the platinum point carried by the mica is plunged forcibly into the mercury in $\mathrm{M}$, and by this means a circuit is completed through the battery and pen, and the pen is deflected, making a record on the drum. The resilience of the mica immediately withdraws the platinum point from the mercury and poises it in readiness for the next drop, so that the current passes only momentarily. In order that water may not accumulate on the mica and so prevent the strip from springing back and breaking the contact, it has been found advisable to slope the mica strip so that the water drains from the end. The mercury retains a film or drop of water upon its surface, which, however, is no disadvantage, since even if the platinum continuously dips into the water, the low voltage (about two volts) required to work the pen produces very little electrolysis, and at the same time the effects of sparking, which occurs when the contact is broken, are lessened.

It has been found that the mica strip tends to oscillate after a drop has fallen, thus making more than one record on the drum. This is not a serious drawback because it is readily detected when it occurs; it is, however, easily prevented by raising the recorder till the tube $\mathrm{R}$ bears upon the mica, thus pressing the platinum point very close to the mercury surface. This is found to damp the oscillations and one record per drop is obtained.

The chief difficulty with the apparatus is that when air has entered the aspirator bottle, temperature changes cause changes in the volume and a consequent alteration in the rate of dropping. To overcome this, it has been found necessary to place the aspirator in a water bath at a constant temperature. An electrically heated bath, constant to $\pm 0.02^{\circ} \mathrm{C}$., has been used and found extremely satisfactory, but such accuracy as this is not essential. It is obvious that a greater volume of air in the bottle entails less accuracy, so that an experiment should be started with the bottle full of water, and refilling should be resorted to as frequently as possible. 
Recently boiled distilled water is used in the aspirator in order to avoid the inconvenient accumulation of air bubbles in the tubes of the apparatus, when the temperature of the water is raised to that of the bath.

A record obtained with this apparatus consists of a series of marks upon the clockwork drum, the distance between two adjacent ones representing the time taken for a drop to be formed and discharged. The distances between adjacent marks will therefore be a measure of the rate at which air is being drawn into, and water out of, the aspirator bottle if the drops are all of the same size. Tests have been carried out to determine the weight of water per drop. Successive single drops were found to vary considerably less than I per cent., and this variation includes errors of collecting and weighing. Variation in the rate of dropping produces variation in the size of the drops-a quicker rate giving larger drops, but this variation is most marked with quick rates. Over the range which has been found convenient in experiment, i. e. not quicker than two or three drops per minute, the variation in size of the drops was again less than I per cent.

In addition to the change in size of the drops, error may result from a change of temperature of the air in the glass or rubber connexions which are not in the water bath, namely the connexion from the leaf-chamber to the air intake-tube of the aspirator bottle. Such a temperature change would result in a change of volume, and consequently of the rate of dropping. To reduce this error to a minimum it is advisable to reduce the volume of air in these connexions to a minimum, by using narrow-bore thick-walled rubber and glass tubing, and to shorten the distance between plant and aspirator as far as possible. If the whole apparatus is shaded from direct sunlight sudden temperature changes will be avoided. A water jacket for these connexions has been contemplated, but it has not been found necessary to resort to this.

Before employing the apparatus for investigation of stomatal changes, many preliminary experiments were carried out, using fine capillary tubes and platinum discs with small punctures in them, in order to estimate the accuracy of the apparatus under constant conditions. No purpose would be served by a full account of these preliminary investigations, but the conclusions drawn from them will be briefly outlined.

Several types of air intake-tube were tried, the air being made to bubble from apertures of various sizes and shapes, but a square-cut end was found to be as satisfactory as any form. Similarly a square-cut dropping-tube ( $\mathrm{E}$ in Fig. I) was found satisfactory.

Slow rates of dropping tend to decrease the accuracy, possibly due to the fact that when a drop remains for some time attached to the droppingtube there is a greater possibility of its being prematurely shaken off, and also greater opportunity for temperature changes to become effective. The most convenient and at the same time accurate rates are from one drop 
per thirty seconds to about one drop per I 20 seconds. In work with plants, the rate can be arranged by selection of the leaf-chamber and regulation of the pressure difference in the aspirator. Naturally, owing to stomatal changes, the rate changes considerably during a day, and very slow rates are unavoidable, but for short experiments in daylight the above-mentioned speeds have been found easy to arrange.

The experiments with fine capillaries and punctured platinum discs gave indications of the existence of a rhythm in the flow of air, and although it was realized that some of the observed irregularities might be due to the capillaries themselves, attempts were made both to determine and to eliminate this rhythm. It was thought to be due to the small pressure changes resulting from the relative sizes of the drop at $\mathrm{E}$ and the bubble at $\mathrm{B}$, and various combinations of sizes of these two tubes were tried, but failed to give satisfactory results. As the period of the rhythm probably changes with temperature and rate of flow, attempts to calculate it were given up, especially as the later experiments upon stomata gave sufficient accuracy without allowing for a rhythm.

It was evident, however, that the disturbing influence of the rhythm was less noticeable with large than with small pressure differences, so that in so far as is compatible with other conditions of the experiment, it is advisable to employ large pressure differences; from 5 to 15 centimetres have been found convenient.

By taking the precautions outlined above, it has been found possible to obtain very satisfactory results with the apparatus: thus, on July 2, I914, with the apparatus attached to a fine capillary tube and a pressure difference of $10 \mathrm{~cm}$., a record running for two hours gave an average distance travelled by the drum during the formation of one drop of $5^{\circ} \circ$ divisions of the paper used (=about $55 \mathrm{sec}$.), the maximum distance for any drop being 5.2 divisions and the minimum $4 \cdot 8$. Typical records obtained with stomata are given in the second part of this paper. Test experiments have also been carried out to compare the records obtained with the apparatus with that obtained with the ordinary porometer by stop-watch readings, of which the following is typical:

Exp. IIo. Five leaf-chambers were attached to one leaf of Maranta coccinea, var. floribunda at 4.30 p.m. on March 4, I9I5. At II.I5 a.m. the next day, two were connected to two recording porometers, and the other three by means of a 4-way tube to a single bubbling aspirator for stop-watch readings (3), which were taken every fifteen minutes. The results are shown in Fig. 2, where the reciprocals of the distances between the two successive marks on the drum and the reciprocals of the stop-watch readings are plotted against time. The recorders of course gave continuous records, but as each curve would involve about $35^{\circ}$ points, only one point for each five minutes period is given. It has been shown in some work which it is 


\section{2 \\ Laidlaw and Knight.-A Description of a Recording.}

hoped to publish shortly, that the stomata upon different parts of a leaf may be considered to behave similarly under similar conditions of illumination, \&c., so that the curves in Fig. 2 are an indication of the relative accuracy of the recording apparatus and the ordinary porometer. The maxima in

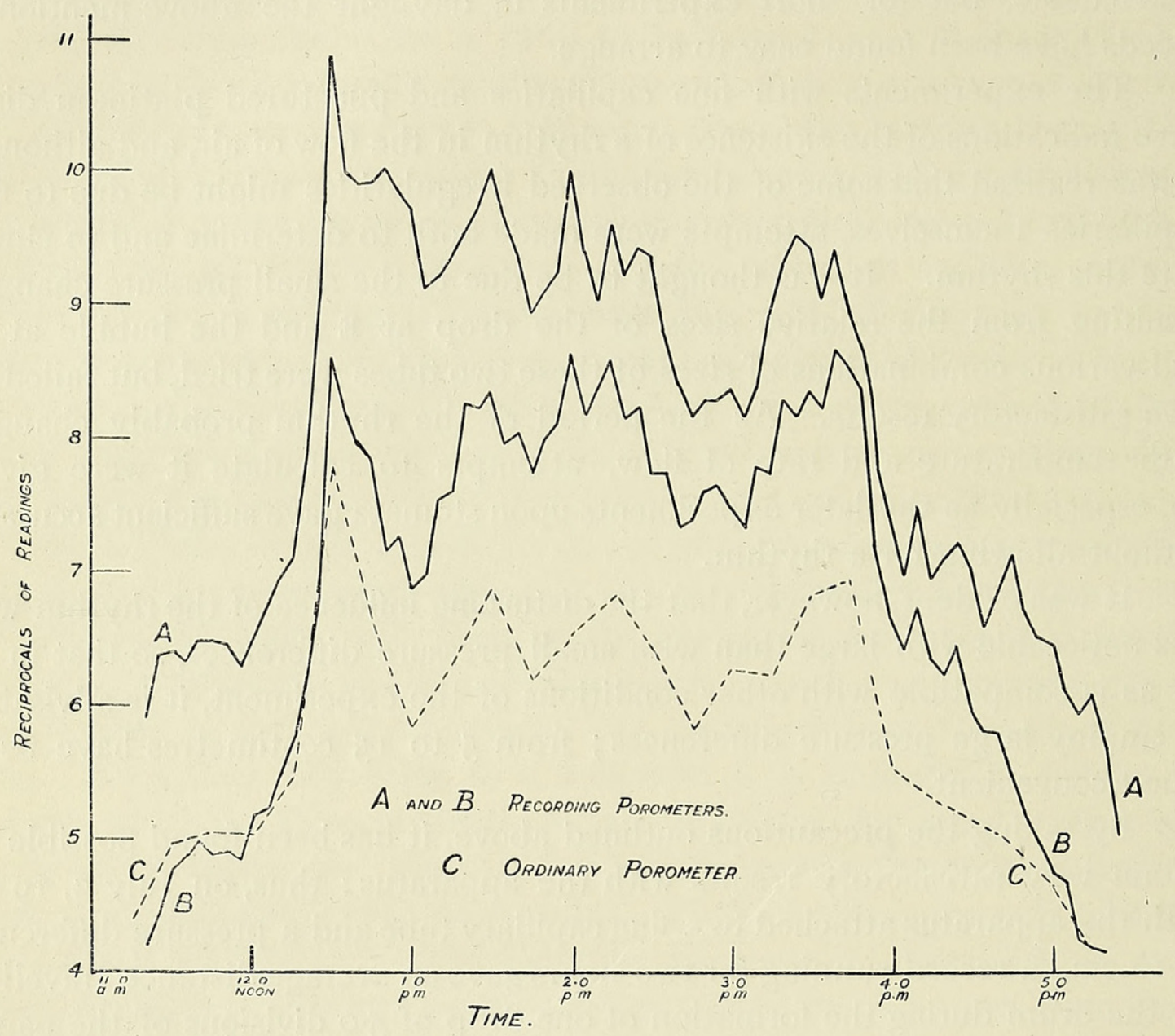

FIG. 2 .

the curve of the latter are repeated in both recorder curves, and altogether here is a striking parallelism.

\section{Stomatal Behaviour DURing Wilting.}

It has been stated by Darwin $(4,5)$ and Darwin and Pertz $(6)$ that, in the case of plants investigated by them, on severing a leaf from the stem and allowing it to wilt, there occurs a temporary opening of the stomata prior to the closure following upon wilting. This preliminary opening has been demonstrated by the above authors by three different methods at different times-by the horn hygroscope, by temperature methods (in which, however, the assumption is made that the amount of transpiration from a leaf is an indication of the condition of its stomata), and also by the porometer method. Lloyd (7), using his alcohol method of stomatal 
measurement, failed to find any indication of the temporary preliminary opening described by Darwin and Pertz.

The recording apparatus described above seemed to adapt itself well to a question of this kind, and consequently experiments were undertaken to investigate it.

The usual method adopted was to attach two leaf-chambers to different leaves of the plant to be investigated, and some hours later-generally the next morning-each was connected to a recording apparatus, and records were commenced. After an interval of an hour or more, one of the leaves was severed from the plant, the other being left attached to the plant to act as a control for temperature, humidity, and illumination changes. The experiment was continued, after severing one leaf, for a period determined by the result, and in many cases the second leaf was also severed later.

The plants used included Maranta bicolor, $M$. coccinea, var. floribunda, Prunus Laurocerasus, Eucharis Mastersi, Eupatorium adenophorum, E. Raffilli, Pelargonium (ivy-leaved), and Phaseolus vulgaris.

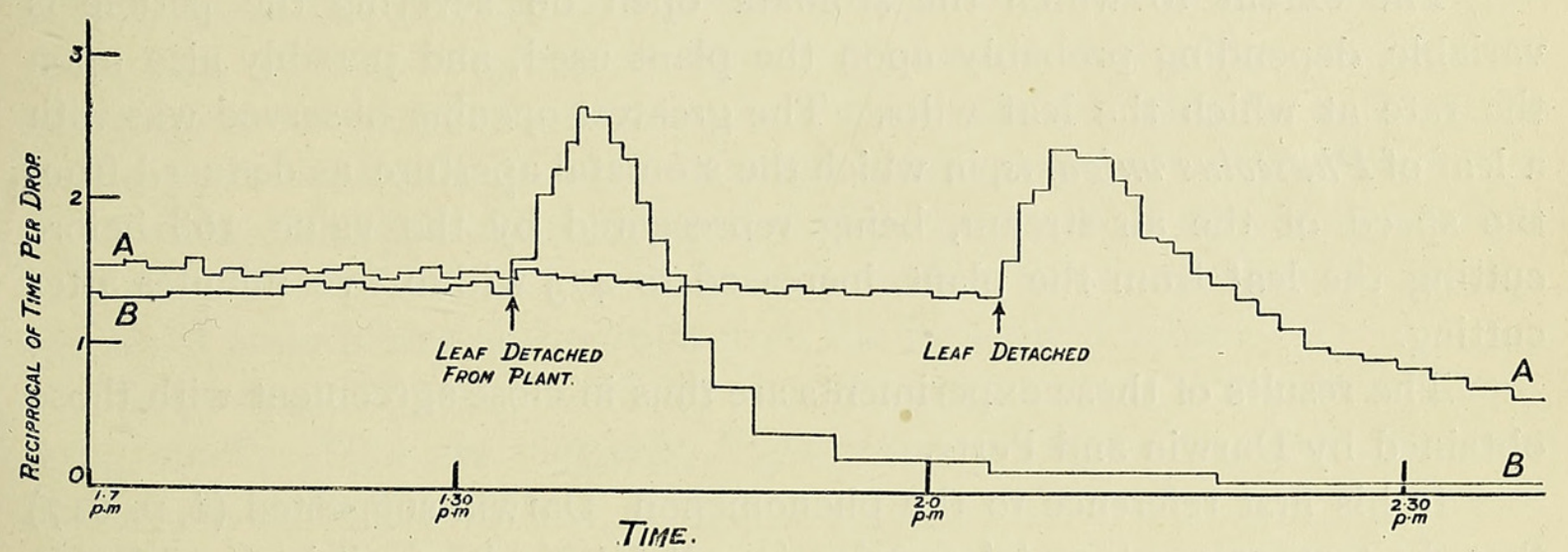

FIG. 3.

With the exception of Eucharis Mastersi all these plants showed the preliminary opening described by Darwin. Only one experiment was carried out with the Eucharis, and it is doubtful if the leaf was appreciably wilted at the end of the experiment, since the lamina is fairly fleshy and has a thick midrib which would hold much water, so that although no preliminary opening occurred in our experiment, further investigation might show that Eucharis is no exception.

Fig. 3 shows the result of one of these experiments upon Phaseolus vulgaris.

The time elapsing between severing the leaf from the plant and the opening movement of the stomata varies considerably with different plants and different conditions, and is apparently dependent upon the rate of wilting. In the case of a thin leaf which wilts quickly, the opening movement occurs very shortly after the leaf is cut from the plant, whilst in a thick leaf the opening may be long delayed. In the curves of stomatal 
aperture shown in Fig. 3, the opening reached a maximum in both cases about five minutes after the severance from the plant, whilst in the case of the thick leaf of Prumus Laurocerasus, even when the temperature was $20^{\circ} \mathrm{C}$., tending to produce rapid wilting, nearly twenty minutes elapsed before the maximum opening was reached.

Similarly, with any particular plant, a higher temperature, tending to produce more rapid wilting, causes the maximum to be reached more quickly, and a roughly graded series may be obtained, as in the following experiments upon Maranta bicolor:

$\begin{array}{cc}\text { Experiment No. } & \begin{array}{c}\text { Mean greenhouse } \\ \text { temperature }\left({ }^{\circ} \mathrm{C} .\right) .\end{array} \\ \text { I00 } & \text { I } 6 \cdot 3 \\ \text { I02 A } & \text { I } 8 \cdot 0 \\ \text { I02 C } & \text { I } 8 \cdot 0 \\ \text { I03 } & 18 \cdot 8 \\ \text { I06 } & 20.5\end{array}$

Time elapsing before max. opening is reached.

35 minutes.
I3 "
I4 "
20
9 "

The extent to which the stomata open on severing the petiole is variable, depending probably upon the plant used, and possibly also upon the rate at which the leaf wilts. The greatest opening observed was with a leaf of Phaseolus vulgaris, in which the stomatal aperture, as deduced from the speed of the air-stream, being represented by the value 168 before cutting the leaf from the plant, increased to 475 within five minutes after cutting.

The results of these experiments are thus in close agreement with those obtained by Darwin and Pertz.

In his first reference to the phenomenon, Darwin suggested (4, p. 6I 7$)$ that the temporary stomatal opening is a direct result of wilting, and is due to the guard-cells retaining their water, and therefore remaining turgid longer than the other epidermal cells. Thus the pressure of the rest of the epidermis upon the guard-cells is reduced early in the process of wilting, with the result that the size of the stomatal pore increases.

The explanation offered by Darwin is no doubt the most probable one, but no experimental evidence was adduced in support of it, and alternatively there seem to be two other possible explanations which would fit the observed facts. The stomatal opening might be due, not to any effect of wilting, but to the shock sustained by the leaf as a result of severing it from the plant. In another connexion it has been demonstrated that the mere handling of some leaves may produce stomatal closure, but opening has never been observed to occur as the result of shock.

Another possibility was that the change in the porometer readings on detaching a leaf from the plant might be due to some cause other than stomatal opening.

In the unpublished work above referred to, it was observed that in 
at least one plant, Eucharis amazonica, it was possible in a porometer experiment with a normal attached leaf, that some of the air drawn from the leaf entered it through the petiole and not through the stomata, since, when all the stomata outside the leaf-chamber were blocked, a current of air could still be drawn through the leaf unless the petiole was severed and blocked, e. $g$. by immersing in water.

It was thought possible therefore that when a leaf was detached from the plant and the petiole exposed, the air-stream might find the path through the petiole of less resistance than formerly. This would result in an increase in the speed of the air-current through the leaf, followed by a decrease when the stomata closed.

If this were the case, it is to be expected that the temporary 'opening' would reach a maximum almost immediately after detaching the leaf. The results show that some minutes elapsed in every case before the maximum was reached, which also confirms the observations of Darwin and Pertz.

This explanation of the phenomenon applies only to the results obtained by the porometer method, but Darwin's experiments with the horn hygroscope and temperature methods (4 and 5) showed clearly that an increase in transpiration occurred when the leaf was detached; this he adduced as further evidence for the view that the stomatal apertures had increased.

Dixon (8) has, however, suggested that the result of detaching a leaf is to reduce the tension in the water columns in the tracheae and thereby permit of more active evaporation from the mesophyll cells.

Experimental tests of these possible explanations were undertaken, using chiefly Phaseolus vulgaris, Eupatorium adenophorum, and Maranta coccinea, var. floribunda.

To prevent any flow of air through the petiole after severing it, the cut end was blocked by various means. Vaseline was found to be unsatisfactory owing to the difficulty of attaching it to the wet surface. Immersion in mercury, and coating the end with a wax mixture, stiff gelatine and stiff glue, were among the methods used to close the cut end of the petiole. The results showed that blocking the petiole by these means did not prevent the usual temporary opening, even though, in the case of the experiments with gelatine, the petiole was cut beneath the surface of liquid gelatine, and the cut end was therefore never exposed to the air. The phenomenon cannot therefore be attributed to the leakage of air through the petiole.

If, however, the petiole is cut below the surface of water, and kept supplied with water, the temporary opening does not occur. Instead there is either a slight tendency to closure, or else the stomata behave quite similarly to those of the control leaf still attached to the plant. Under these conditions the leaf does not visibly wilt in the course of several hours, or at most is only slightly less turgid than the leaves attached to the plant.

This result disposes of the possibility of shock being responsible for the 
temporary opening, since severing the petiole beneath gelatine cannot cause more or less shock than severing it beneath water, and yet in the one case the opening occurs, and not in the other.

At the same time it is shown that when the leaf does not wilt the effect of severing it from the plant is practically nil.

From our experiments, therefore, it appears that when a leaf is detached from the plant and allowed to wilt, the stomata open for a short time before finally closing, and these results are quite in accordance with the observations of Darwin and Pertz.

In addition, some direct evidence has been obtained in support of the explanation of this phenomenon offered by Darwin, viz. that it is the direct result of wilting probably due to the guard-cells retaining their turgor longer than the other epidermal cells.

Neither stomatal closure due to shock nor the entrance of air into the leaf through the petiole can account for the increased porometer readings after detaching a leaf.

\section{Summary.}

I. A description is given of a modification, making it self-recording, of the aspirator porometer described earlier.

2. Experiments on various plants confirm the observations of Darwin and Pertz-that on detaching a leaf from the plant and allowing it to wilt, the stomata open temporarily before finally closing.

3. Evidence is adduced in support of Darwin's suggestion that this phenomenon is due to wilting.

Department of Plant Physiology and Pathology, Imperial College of Science and Technology.

\section{REFERENCES CITED.}

1. Balls, W. L. : The Stomatograph. Proc. Roy. Soc., vol. B. 85 , I912, p. 33 .

2. Neilson Jones, W.: A Self-recording Porometer and Potometer. New Phytologist, vol. xiii, I9I 4, p. 353 .

3. Knight, R. C.: A Convenient Modification of the Porometer. New Phytologist, vol. xiv, I9I5, p. 2 I 2 .

4. Darwin, F.: Observations on Stomata. Phil. Trans., vol. B. I90, I898, p. 548 .

5. A Self-recording Method applied to Movements of Stomata. Bot. Gaz., vol. xxxvii, 1904, p. 89 .

6. Darwin, F., and Pertz, D. F. M.: New Method of Estimating the Aperture of Stomata. Proc. Roy. Soc., vol. B. 84 , I9I I, p. I49.

7. Lloyn, F. E.: Physiology of Stomata. Carnegie Institute Publications (Washington), No. 89, I 908 , p. $8 \mathrm{I}$.

8. Dixon, H. H. : Transpiration and the Ascent of Sap in Plants. Macmillan's Science Monographs, I9I4, p. I24. 

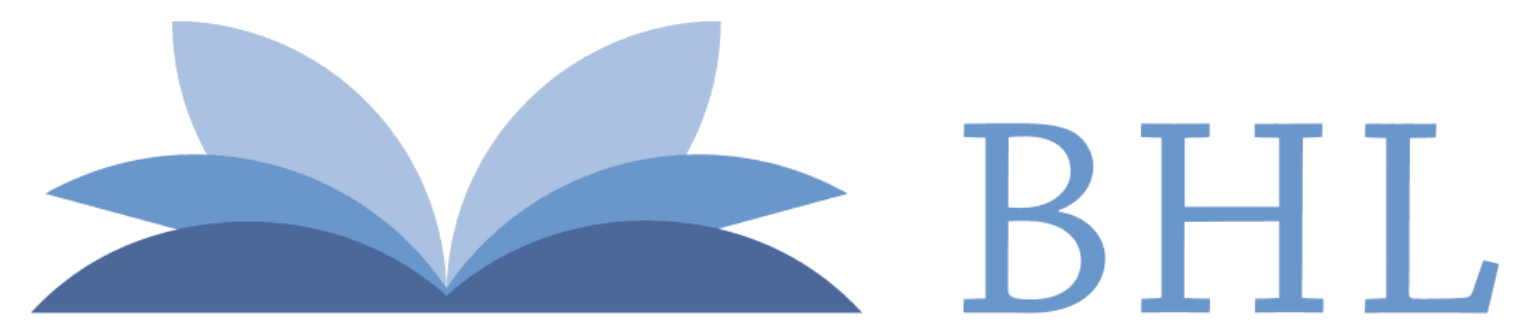

\section{Biodiversity Heritage Library}

Laidlaw, C. G. P. and Knight, R. C. 1916. "A description of a recording porometer and a note on stomatal behaviour during wilting." Annals of botany 30, 47-56. https://doi.org/10.1093/oxfordjournals.aob.a089588.

View This Item Online: https://www.biodiversitylibrary.org/item/237452

DOI: https://doi.org/10.1093/oxfordjournals.aob.a089588

Permalink: $\underline{\text { https://www.biodiversitylibrary.org/partpdf/320095 }}$

\section{Holding Institution}

Smithsonian Libraries

\section{Sponsored by}

Biodiversity Heritage Library

\section{Copyright \& Reuse}

Copyright Status: Not in copyright. The BHL knows of no copyright restrictions on this item.

This document was created from content at the Biodiversity Heritage Library, the world's largest open access digital library for biodiversity literature and archives. Visit BHL at https://www.biodiversitylibrary.org. 